In Philip Boyes, Philippa Steele, and Natalia Elvira Astoreca (Eds.), The social and cultural contexts of historic writing practices (pp. 55-72). Oxford: Oxbow Books.

\title{
A Cognitive Archaeology of Writing: Concepts, Models, Goals
}

\author{
Karenleigh A. Overmann \\ University of Bergen and \\ University of Colorado, Colorado Springs
}

Think about what happens as these words are read: Hands turn or scroll the page, eyes move over the writing, and psychological processes turn the written forms into the words and sentences of a specific language. The process can be described as a dynamic interaction between body, brain, and material form. What this description fails to characterise adequately is the agency of the material form: It elicits specific behavioural and psychological responses in its users, capacities they gain as they become proficient in interacting with it-that is, as they learn to read and write. How does a material form like writing become able to influence the behaviours and psychological processing of its users? As its form changed under the gradual pressure of generations of tinkering and adjustment, it accumulated the cognitive effort of past generations and redistributed it to future ones, who simply learned to use the tool and modified it further in the course of use. Yet in the moments of interaction — when we read and write-writing still seems as static, as permanent, as if it were carved into stone. Its form does change, only more slowly than our experience of it suggests. These are aspects of writing that demand further investigation.

If ancient cognition cannot be studied directly, material forms do provide insight into some of the associated behaviours and psychological processing of the ancient peoples who once made and used them. Writing, obviously, implies behaviours like handwriting and psychological processes like vision and language. When interpreted through neuroscience, change in writing implies associated change in the behaviours and brains that produced it. Such analysis requires two things: first, a material record with enough duration and extent to show change over time in detail, and second, a cognitive state understood well enough that change in material form can suggest change in behaviours and brains.

Literacy is such a cognitive state, and Mesopotamian writing has a sufficient record of material change to suggest, at least in broad outline, how literacy developed. While literacy is commonly defined as the ability to read and write, this assumes a script, writing that is capable of representing language with fidelity. Script stands in contrast with the initial state of writing, which represented language much less faithfully-so poorly, in fact, there is debate over whether that language was Sumerian or Akkadian (Englund 1998; Hyman 2006; Veldhuis 2014). Early Mesopotamian writing took the form of pictures and signs. These were meaningful either because they depicted an object or they had an agreed-upon meaning, a social convention. For example, a picture of a jar meant jar because it looked like one, and a quartered circle meant sheep because everyone agreed it had that meaning. This functional literacy depended on this-means-that associations acquirable with far less behavioural and psychological change than what is involved in true literacy, the ability to interact with written forms that do not depend on resemblance and convention. How the initial cognitive state involving early writing yielded literacy and script required change in all three dimensions: the behaviours and psychological processes of the writers and the material form of writing itself.

The idea is that cognition is a dynamic system composed of brains, bodies, and materiality, in which influence among the components is multi-directional. Interaction with material forms changes behaviours and brains. Change in behaviours and brains enables further 
change to material forms. And material forms accumulate the cognitive effort of past generations and act as a medium for recreating those changes in present and future generations. There is a social aspect to such change as well: In realising literacy and script from early writing, a society had to its behaviours with a specific material form over multiple generations. The material form also had to be malleable enough so its form could change as behaviours and brains reorganised.

Such analysis requires a theoretical framework that can reconcile interdisciplinary data from the neuroscience of literacy and the archaeological and textual records of the Ancient Near East. In the analysis that follows, the framework applied is Material Engagement Theory (Malafouris 2004). MET has three central commitments. First, minds are considered extended and enactive. Extended means that material resources may be at least partially constitutive of cognition (Clark 2008; Clark and Chalmers 1998). Enactive means cognition is the dynamic interactivity between brains, bodies, and materiality (Hutto and Myin 2013). Reading is an excellent example of cognition that is extended and enactive, since it is difficult to imagine how we would read without the material form that is writing. Second, materiality is viewed as influencing change in behaviours and brains. That is, material forms have agency (Jones and Boivin 2010; Kirchhoff 2009; Malafouris and Knappett 2008; Newen, De Bruin and Gallagher 2018). Reading is a good example here as well, as there are specific behavioural and neurological reorganisations associated with learning to read and write, such that interacting with the material form that is writing changes behaviours and brains. Third, materiality is meaningful in a way that differs from language: It is meaningful in virtue of what it is and what we do with it (Malafouris 2013). Writing is an interesting material form because, as it acquires fidelity to language, it becomes more language-like in how it means, signifying rather than resembling or instantiating. In the analysis presented here, the focus will be on the second and third of MET's central commitments, the agency and semiotic function of the material form that is writing.

An initial MET analysis of change in the material form of Mesopotamian writing (Overmann 2016, 2017) yielded a model of how literacy might develop: from the behaviour that is handwriting, with a material form malleable enough to permit incremental change occasioned by changes in behaviours and psychological processing, and within a specific social context that sustains the behavioural interaction with the material form for generations. After the model is reviewed, it is critiqued in terms of its original development, goals and shortfalls and potential for future expansion. A particular area of expansion is then explored: the way distinct neurofunctional and behavioural pressures influence written forms for language and numbers, thereby affecting how such forms change across languages and cultures (Overmann 2020).

\section{A Model of How Writing Changed in Mesopotamia, and the Cognitive Implications}

The initial model of how writing changed over time and the cognitive implications of that change used Mesopotamia as its case study (Overmann 2016). Data on Mesopotamian writing were compiled from the literature and sorted into seven categories, from the making of dictionaries known as lexicography to the identifiability of language (fig. 4.1). These data were then mapped across time and cultural periods to examine what was changing and when and get a sense of how writing changed as a system. If the plot was initially difficult to create, it must be noted that when it is turned on its side, it resembles a standard archaeological chronology. 


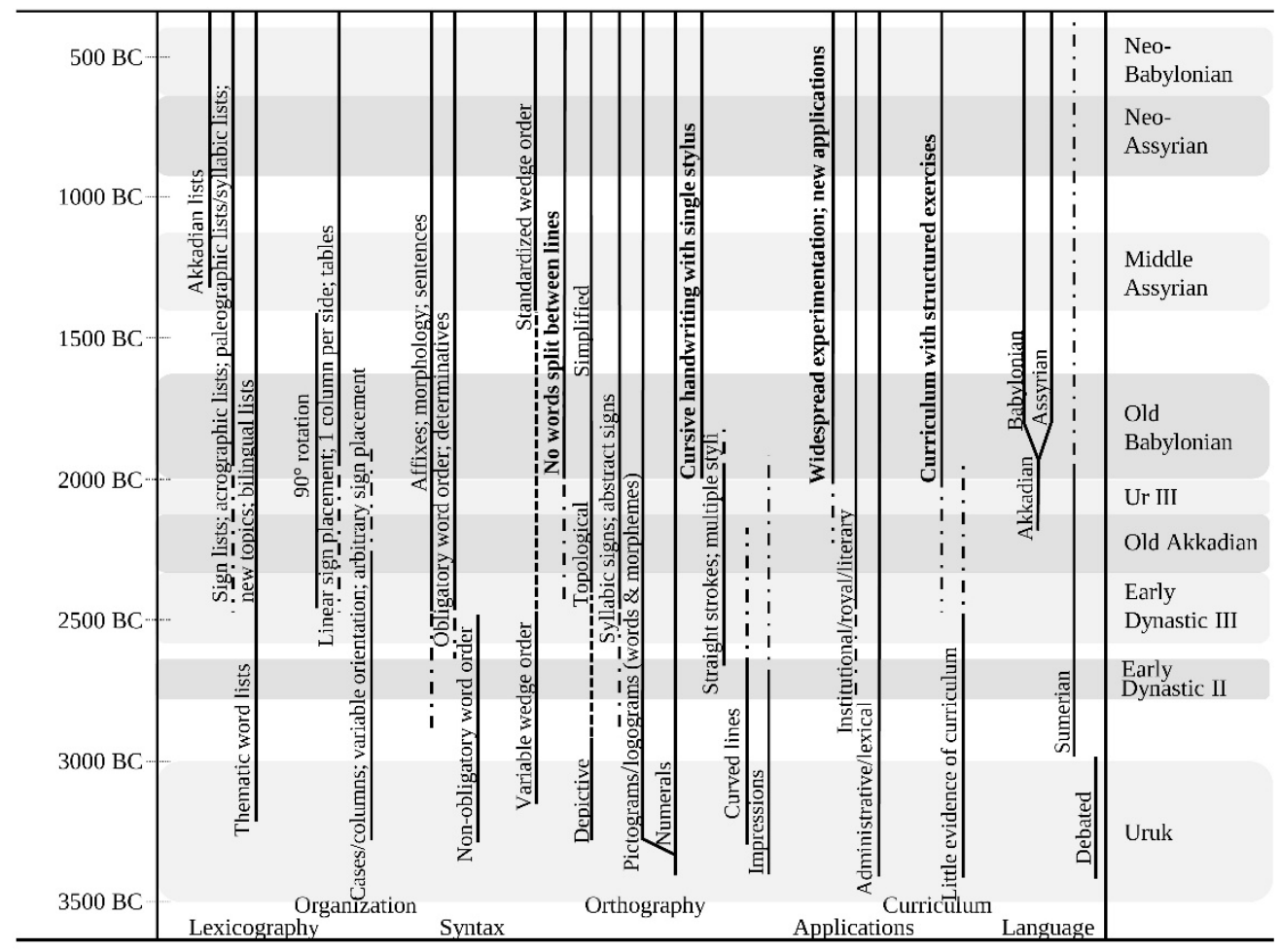

Fig. 4.1. Model of Mesopotamian literacy. The seven categories or dimensions of change in the system of writing include lexicography, dictionary-like compilations of words; organisation, the layout of words upon the surfaces of writing materials; syntax, the ways in which characters, words and phrases are arranged to reflect language; orthography, conventionalisations of signs and sign combinations; applications, the purposes to which writing and scripts are applied; curriculum, the systemisation of training; and language, the degree to which the language expressed is identifiable. The data were sourced from Bramanti (2015), Cooper (1996, 2004), Englund (1998), Hyman (2006), Krispijn (2012), Schmandt-Besserat (1992), Taylor (2011, 2015) and Veldhuis (2011, 2012, 2014). Updated version of the graph originally published as fig. 9 in Overmann (2016, 297). Additional data were added, and the graph has been rotated anticlockwise $90^{\circ}$ to emphasise its resemblance to an archaeological chronology. All rights reserved.

Understanding how change in written form is informative regarding change in behaviours and brains starts with what differentiates a literate brain from one that is not literate. In literacy, the region of the temporal lobe that recognises physical objects, the fusiform gyrus, becomes trained to recognise written characters as if they were physical objects, interpret them through the gestures of handwriting and associate them with the meanings and sounds of language (Dehaene and Cohen 2007, 2011; McCandliss, Cohen and Dehaene 2003; Nakamura et al. 2012; Perfetti and Tan 2013). This neurofunctional reorganisation is common across writing systems, whatever their form and regardless of whether signs map to words, syllables or phonemes.

Among the changes in the material form of writing, one of the most dramatic is the loss of depictiveness. Early signs resembled objects; later signs did not (fig. 4.2). This change has been characterised as becoming "increasingly schematic" or abstract (Schmandt-Besserat $1978,50)$, though "abstract" is one of those squishy terms that means different things in different contexts. Here it means less depictive, and it suggests that brains were learning to recognise characters as objects. Objects are recognised through combinations of their local and global features. This works as follows. In fig. 4.3 (left), readers might see a cube in the combination of features, though the lines are not actually there. Local features are the circles and cut-outs, global features, the relations between them. Recognising words is similar. Readers will likely see the words THE CAT in fig. 4.3 (right), though the middle characters are neither $\mathrm{H}$ nor $\mathrm{A}$. Meaning is derived from the characters themselves, the context of the 
adjacent characters forming words and learned associations between written forms and language. Trained object recognition and learned lexical associations account for variability in script forms and mapping, as the potential for an object to be recognised through its features and associated lexically is independent of its actual form.

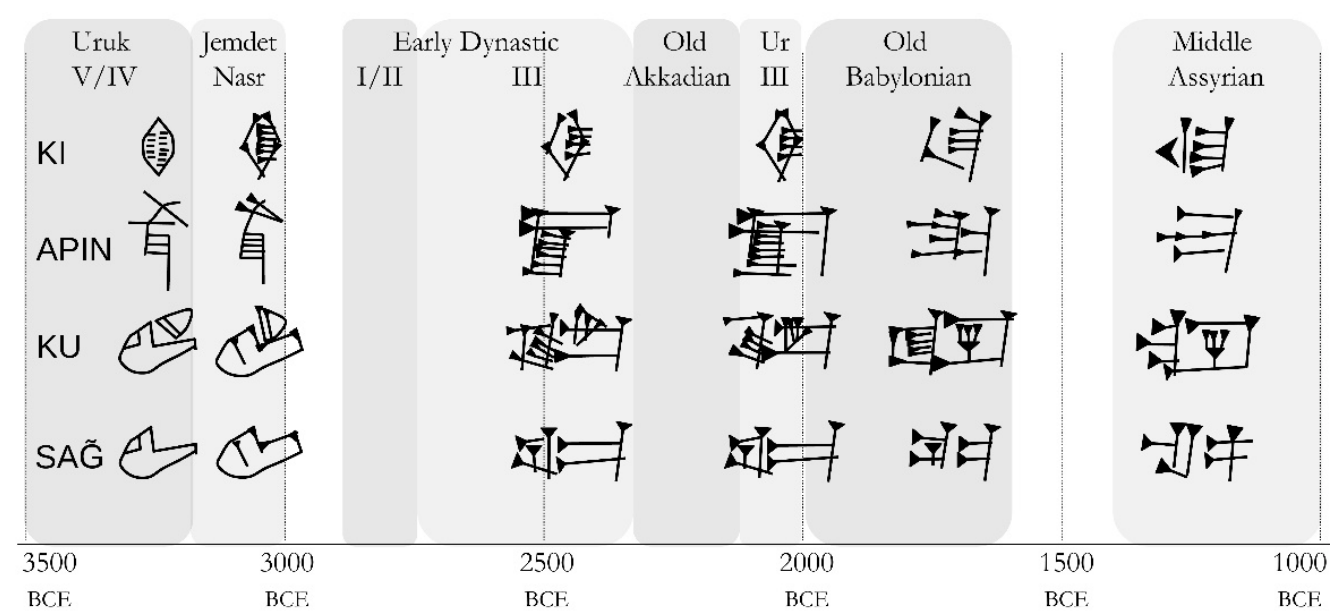

Fig. 4.2. Chronology of signs showing change in form. Early signs (left) are recognisably depictive and differ in obvious ways from one another, while later signs (from $2400 \mathrm{BC}$ and thereafter) are less depictive, and the clues differentiating them are more subtle. Key: Uruk period, 3500-3000 BC; Early Dynastic (ED) II, 2900-2700 BC; ED III, 2700-2340 BC; Old Akkadian (OA), 2340-2200 BC; Ur III, 2100-2000 BC; Old Babylonian (OB), 19001600 BC; Middle Babylonian (MB), 1400-1100 BC; Middle Assyrian (MA), 1400-1000 BC. Adapted from fig. 88 in Nissen, Damerow and Englund (1993, 111). All rights reserved.

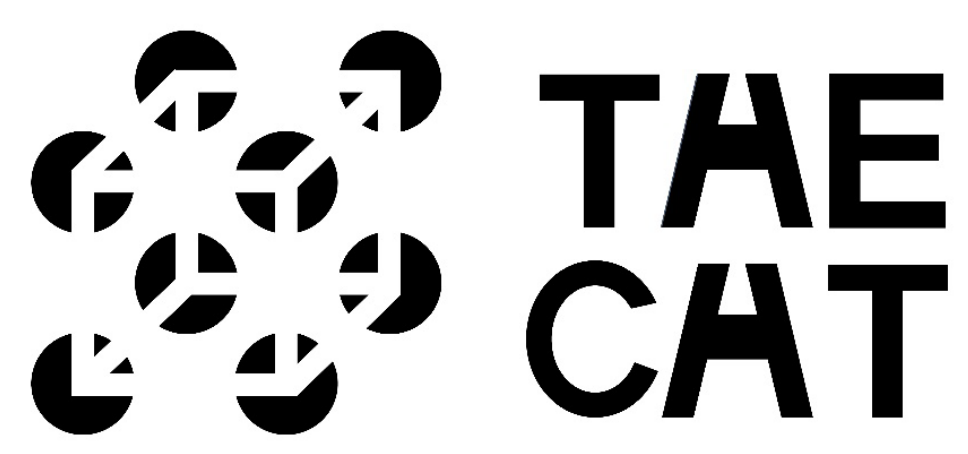

Fig. 4.3. Feature recognition of objects and writing. In both, recognition is a matter of local detail and global cues. On the left, a cube is recognisable in the circles and cut-outs (local details) and relations between them (global cues). On the right, the words THE CAT are recognisable; meaning is derived from the characters themselves (local detail), the context of adjacent characters (global cues) and learned associations between written forms and language. Originally published as fig. 2a in Overmann (2016, 288). All rights reserved.

As brains became trained to recognise features and associate lexically, the need for the characters to depict was relaxed. That is, as characters became topologically recognised, they could deform. This in turn allowed characters to become more alike and simpler.

More alike means there was still some resemblance between early and later written forms (fig. 4.2). However, the later forms are closer in appearance to each other than the early forms were. That is, the clues distinguishing early signs are more obvious than the clues distinguishing later signs. Visual discriminability and individuation-being able to tell characters apart and identify single characters as themselves-depend on familiarity. With familiarity, objects become easier to tell apart, so the distinguishing clues can become more subtle. These effects are also found in facial recognition, particularly across ethnic groups, 
where they affect things like eyewitness identifications (Brigham et al. 2007). Topological recognition lets characters lose their depictiveness, while differentiating in ways that enhance the ability to tell them apart. The range of total variability decreased, while characters converged on points of maximal contrast. This is the process whereby graphic elements become a contrastive system. This process occurs without change to the way graphic elements are mapped to language, so writing can become a contrastive system whether it is logographic, syllabic, alphabetic or some combination. This change also shows why training had to become more formal: Written characters became too much alike. It had been relatively easy to tell the earlier pictures apart and approximate their meaning through resemblance and knowledge of conventions. But as characters became more alike, the differences between them were too subtle for anyone who lacked familiarity, and gaining the requisite familiarity required training.

Simpler means characters lost some of their detail toward the end of the chronology shown in fig. 4.2, suggesting an optimisation or balance of local and global detail. Local detail helps novices but slows proficient readers, who make greater use of global cues. In later writing periods, local details were omitted, suggesting readers made greater use of global cues. This had another benefit: The more detail characters have, the longer they take to write, and omitting detail enabled the speed of production to increase to the point where writing could become a more interactive medium with thought. In modern scripts, this same effect of a trade-off between local detail and global cues is found in diacritics for tones in African languages (Bird 1998, 1999; Koffi 2014) and vowels in Hebrew (Ravid and Haimowitz 2006). Discussion involves the potential for having different forms of written language, one for novices and one for proficient readers. Of course, the trade-off is that readers have to learn both.

Handwriting involves motor movements controlled by Exner's Area of the brain (Roux et al. 2009). Exner's Area is thought to help us recognise the gesture in the written word, a mental simulation (Konnikova 2014). Its activity is particular to handwriting, not just any fine work involving the hand, so while it is possible to produce characters by, say, carving them in stone, carving differs in both the movements used and the character repetition involved. Writing by hand improves fine motor skills, hand-eye coordination, recognition and recall functions, lexical retrieval and tolerance for ambiguity in how characters are formed (Giovanni 1994; James and Engelhardt 2012; Longcamp, Zerbato-Poudou and Velay 2005; Sülzenbrück et al. 2011). In the emergence of literacy, handwriting was critical. Not only did it realise improvements in these functions, it afforded a mechanism for continual adjustment of the material form, which was essential to the system's ability to change. Change in handwriting also implies things like standardisation, automaticity and tolerance for ambiguity in character form.

Standardisation is forming each character with particular strokes in a particular order. When writing first began, there was no such protocol; standardisation emerged gradually (Bramanti 2015; Taylor 2015). It is seen in the strokes used and the order in which they were made, which become increasingly codified. Over time, these codifications show production becoming standardised, and standardisation shows handwriting behaviour becoming habitual and automatic. Automaticity frees up cognitive resources like attention and working memory (Logan 1992; Tucha, Tucha and Lange 2008). The same thing occurs when someone learns to drive (Charlton and Starkey 2011). A novice driver must pay significant attention to operating the car and conditions on the road. Proficient drivers attend less to these things, becoming alert only when conditions change. In writing, automaticity lets authors focus on what they write, its content, rather than how, its production. This helps transform writing from a tool that simply records mental content to one that lets writers engage it directly.

When people write by hand, they develop a tolerance for ambiguity in how characters are formed (Longcamp et al. 2005). That is, the writing can become sloppier, while readers can 
still recognise it. This lets writers recognise characters, while providing early writing an important mechanism for change. This tolerance is one of the things educators fear will be lost as we type more and handwrite less (Konnikova 2014), though arguably, the loss will be offset by the standardised appearance of characters on screens, and the things computers do really well that handwriting cannot, like speed and networking and information lookup and emotional expressiveness (e.g., emoticons).

Being able to recognise characters even when they are ambiguous is an essential element of developing cursive, a form of writing that trades accuracy of form for speed of production (Veldhuis 2011). Fast writing keeps up better with the speed of thought, so that writing becomes a highly interactive engagement between mental content, material form and behaviours interfacing the two. Characteristics of clay surfaces and writing implements also influenced how characters were made. Making lines or impressions on clay produces furrows, which is how their order of production is determined (Cammarosano 2014). Furrows also mean that characters had to be relatively simple and made with deliberation, since complex characters and characters made in haste quickly yield an illegible mess. In turn, simplicity improved speed of production, while deliberation improved legibility and reduced error. Simplicity also influenced production at a fundamental level. Characters taking hours to make would not record or communicate information efficiently because of their restricted volume, nor would they support the recombination needed to produce new signs.

Over some 15 centuries, the cognitive system changed from a functional reading and writing, in which language was not very fluent, to a state more akin to the literacy we enjoy, where the material form represents language with fidelity. These threads can be detected among the data (fig. 4.1): Characters lost depictiveness and then simplified, suggesting written objects were being recognised by their features and becoming a system of contrastive elements with an optimised balance of local and global cues. How characters were made converged on wedges, improving legibility, visual discriminability and individuation, and handwriting became standardised, suggesting automaticity. By 2000 BC, a literacy on par with what we mean by the term appears to have developed. Words were no longer being split between lines of text (Cooper 1996), a contiguity and integrity of form consistent with object recognition. Cursive developed (Veldhuis 2011), showing a tolerance for ambiguity and enabling an even greater speed of production. Experimentation was widespread, with writing applied to many new purposes (Veldhuis 2012), a concern with content suggesting automaticity had repurposed cognitive resources like attention. And training became highly formal (Veldhuis 2014) because script could no longer be read without it. As the figure shows, the types and rate of change also decreased around this time.

\section{The Initial Model: A Critique}

The initial model provides some unique insights about the way literacy emerged in Mesopotamia from the behaviour of handwriting. First, it suggests that developing literacy involves an initial repertoire of signs with conventionalised "this-means-that" associations. These must be written by hand enough hours per day and days over time to train object recognition and afford automaticity. Signs must be simple, and the material form malleable enough, to enable production, repetition, recombination and change. Finally, signs must not be numerical, as numbers lack the lexical range, the need to include phonography and the ambiguity required to motivate the pursuit of greater linguistic fidelity.

Beyond detailing the emergence of literacy from chronological change in writing, the model illuminates something about our relation with material culture and its role within the human cognitive system. Forget, for the moment, that writing subjects language and ideas to 
analysis and communicates them across space and time (Hutchins 1995; Olson 1994). Instead, consider only its material form. It is difficult to imagine what sort of thing literacy could be without the material form and the behaviours that engage it. Interaction with the materiality of writing engages specific behaviours and psychological capacities. Over centuries of adjustment, the material form has become adept at eliciting specific behavioural and psychological responses. And yet while it changed, the material form remained synchronised to common behavioural and psychological capacities because it passed through the many hands of multi-generational collaboration. It embodies and makes available the change in behaviours and psychological responses realised and accumulated by past generations. It acts as a medium for recreating those changes in present individuals, as they learn to interact with it. And through characteristics and mechanisms like malleability and contrasts of form and structure, it affords possibilities for future change.

The model of how writing changes and what the changes imply cognitively has the potential to be expanded further. Its development was exploratory and unguided, suggesting any expansions and revisions should be less idiosyncratic. Further, the model does not currently distinguish unintentional from deliberate change, or direct from indirect influences. It does not examine the effects of linguistic structure (Coulmas 2003), nor consider selective, artistic or playfulness aspects to iconicity. Factors explainable psychologically and behaviourally, like standardisation and loss of depictiveness, seemed more critical to the process than ones that cannot be so explained, like lexicography. But explanatory ease is not the right criterion, and data should not be discarded from the model until it is been applied to at least one other case. It would also be desirable to specify more clearly the factors included and their level of detail, as well as the criteria for assessing the attainment of literacy.

As noted in its initial publication (Overmann 2016), Mesopotamian literacy is unlikely to represent a universal process. In Egypt, where writing emerged at about the same time and in close geographic proximity, the written form underwent not one but two phases of standardisation and losing depictiveness and detail, assessed by contrasting hieroglyphs with hieratic and demotic. Where Mesopotamian writing developed from administrative practices, Egyptian writing was more aligned with religious and state purposes, things affecting writing behaviour and likely influencing how quickly the respective systems changed. Incorporating cases like Egypt into the model will help gain traction on the critical changes, temporal sequencing and functional interdependencies inherent in the process of developing literacy.

\section{Expanding the Model: Written Change in Literacy and Beyond}

Beyond the improvements suggested in the previous section, the model might be expanded in at least four ways. Two potential areas for future investigation in the way literacy develops were suggested by Kelly (2019). First, in the case of nine scripts invented by non-literate individuals in the past two centuries, literacy emerged within a matter of decades or even fewer years, compared to the millennia or longer associated with ancient literacy. One possible explanation is teleological. In modern contexts, literacy is known and understood, so its appreciation and the role of writing and practice in achieving it guide a new script's invention, even when the individuals involved might not be literate themselves. In contrast, in ancient times, no such guiding teleology existed or would have been possible, so the cognitive state emerged incrementally from socially distributed interactions with the material form. Second, there is a relation between sign variability and the size of the inventory of signs in a writing system, and this may bear on assessing the attainment of literacy, as it has implications for the way writing develops as a relational system. 
A third area in which the model might be expanded is in the collectivist effects produced by the social use of tools (Overmann 2020; Overmann and Wynn 2019a, 2019b). The model of Mesopotamian literacy shows that sustained, societal investment in specific behaviours and material forms yields cognitive change and creativity that cannot be realised by single individuals or generations alone. This suggests that current models of tool use and cognition should expand beyond the individual to the group.

Cognitive aspects of tool use have been modelled with blacksmithing (Keller and Keller 1996), pottery (Malafouris 2008) and stone tools (Malafouris, 2010; Wynn \& Coolidge, 2010). These individualistic models emphasise the individual in terms of performative skill, expertise and aha! moments creating insights (Malafouris, Gosden and Overmann 2014; Wynn and Coolidge 2014). Tools structure and intensify behaviours and select individuals to specific tasks and social roles (Overmann 2016). The individual model does not, however, represent social aspects of tool use. Considered socially, tools are a collaborative medium that influences group behaviours and brains toward common change. Group tools also create communities of specialists, people able and identified for using particular tools who use them in collaboration with one another.

Group use also has an effect on tool form. Though human behaviours and brains have much in common, people differ in their psychological, physiological and behavioural attributes. Most individual variability cancels itself out-highs counteract lows-keeping tool forms synchronised to average capabilities while allowing tool forms to change. Synchronisation in turn distributes the average to new users, influencing cohesion in the group. Cumulative variability yields tools that remain widely accessible, despite change in form. For example, reading and writing require no unusual capacity in psychological processes like attention, nor physiological attributes like fine motor control (obviously, this means the basic ability to read and write, not the ability to engage all the conceptual domains made accessible by writing).

A fourth way the model might be expanded is in numbers, since numerical notations differ from writing for language in several respects (table 4.1). Numeracy and literacy are dissociable phenomena. That is, while some cultures have developed both, many societies develop numbers without writing and a few have developed writing without numbers (Chrisomalis 2010). They are (doubly) dissociable in a psychological sense as well, something that shows they are cognitive functions subserved by distinct parts of the brain (Brannon 2005; Carreiras et al. 2015; Varley et al. 2005). These differences have implications for the forms that signs take, as well as for the ways in which these forms change over time and as they are transmitted across languages and cultures.

There is a fundamental difference in how signs for numbers mean, compared to signs for words that are not numbers. This difference appears in writing from its very inception: Early signs for quantity were repeated, signs for commodity were not (e.g., VA 13629, an administrative tablet from the Uruk V period [3500-3350 BCE], contains nine N01, meaning the number nine, and one UDU sign, meaning sheep). This is because numerical signs instantiate quantity. That is, four wedges are four; six cones are six. Their quantity is unambiguous, even across languages, so these signs do not need to be specified further, even when conventions are added to show grouping (as in a sign that means six or ten of a lowervalue unit) or to differentiate integers from fractions. In comparison, pictographs signify their meaning through resemblance, ideographs through convention. This makes these signs ambiguous regarding the words they mean, necessitating the invention and incorporation of strategies like determinatives and phonography that specify the intended words by altering the visual appearance of the signs. 


\begin{tabular}{|c|c|}
\hline ions & Writ \\
\hline 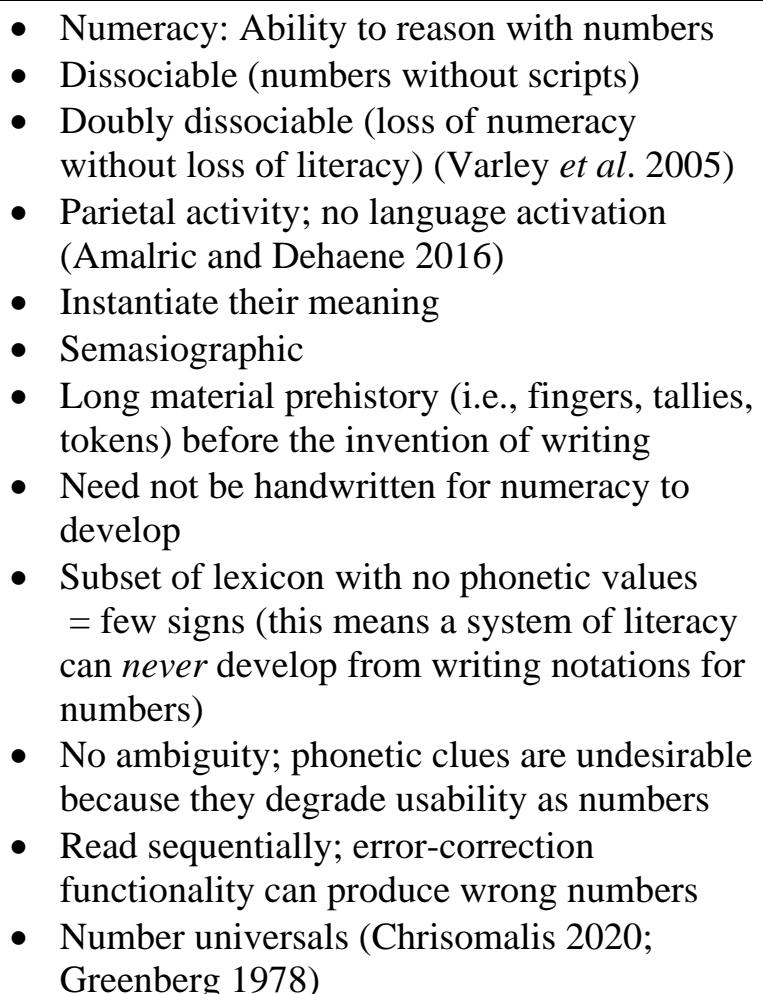 & $\begin{array}{l}\text { - Literacy: Ability to read and write } \\
\text { - } \quad \text { Dissociable (scripts without numbers) } \\
\text { - } \text { loubly dissociable (loss of literacy without } \\
\text { - } \quad \text { Brain activity for language functions } \\
\text { (Perfetti and Tan 2013) } \\
\text { - Signify their meaning } \\
\text { - } \text { Glottographic } \\
\text { - No material prehistory before writing is } \\
\text { - } \text { invented } \\
\text { - } \text { of mast be handwritten as a critical component } \\
\text { - Entire lexicon and phonetic values required } \\
\text { = many signs (this means literacy may } \\
\text { develop, and may also include writing the } \\
\text { - } \text { phonetic values of number words) } \\
\text { - } \text { words intended are required } \\
\text { - } \text { Read holistically, with error-correction } \\
\text { functionality (Rayner et al. 2006) } \\
\text { Language universals (Comrie 1989) }\end{array}$ \\
\hline
\end{tabular}

Table 4.1. Differences between numeracy and literacy. These differ in several respects, including the conditions under which they emerge, the material forms used in their representation and manipulation, their mode of representation, and the neural activity associated with their psychological functioning. The list is not exhaustive of the differences between the two. All rights reserved.

Instantiation makes written numbers contiguous with numbers that are not written. This contiguity with prior forms has no counterpart in non-numerical language. That is, three fingers, three beads on an abacus, three cuneiform wedges and the three strokes of the Roman numeral III are three. Instantiation is meaningful without the phonetic component of language, making numbers a semasiographic system. Semasiographic notations like numbers and music can be read in any language because they are semantically meaningful but not phonetically specified, allowing for radically different choices of words and syntax (fig. 4.4). The expression $2+2=4$, for example, can be put into words - with equal plausibility — as "two plus two equals four," "the number two added to itself yields four," "four is the sum of two and two," "deux plus deux est quatre," or "liăng jiā èr shì sì."

The lack of any need for phonetic specification meant that the Sumerian words for numbers went unrecorded for nearly a thousand years after writing was invented. Further, when the phonetic component of number words was recorded, it appears to have been a response to a very specific circumstance: In the middle of the 3rd millennium BC, Semitic-speaking scribes in the city of Ebla apparently felt the need to learn the Sumerian number words in addition to the Sumerian notations (Edzard 1980; Friberg 1986; Pettinato 1981). This is much like someone today might learn the Latin words for numbers-īnus, duo, trēs, quattuor, quīnque, ... ündecim, duodècim, trēdecim, quattuordecim, quīndecim, ... duodēvīgintī, ündēvīgintī, vīgintī-in addition to the Roman numerals I, II, III, IV, V, ... XI, XII, XIII, XIV, XV, ... XVIII, XIX and XX (Overmann 2020). 


\section{Semasiographic}

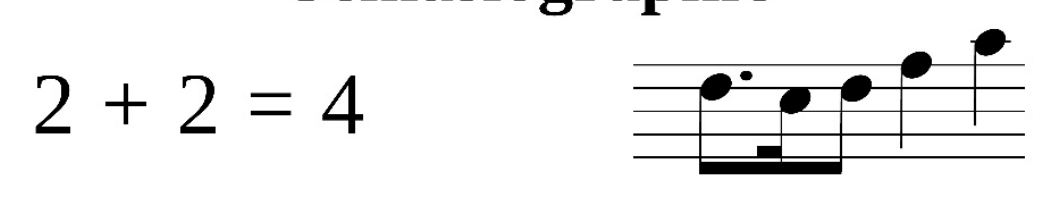

\section{Glottographic}
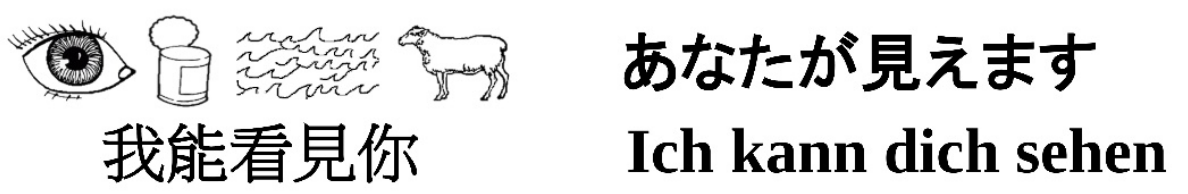

Fig. 4.4. Semasiographic and glottographic writing. While semasiographic notations (top) like numbers are developed in linguistic contexts - that is, the people making and inventing them undoubtedly speak a language (Hyman 2006) - these notations carry no phonetic clues to the actual words. Examples include numbers and musical notations. In contrast, glottographic forms (bottom) are tied to specific words in particular languages, like the words "I can see you" in English (rebus writing), Chinese (logographic), Japanese (syllabic) and German (alphabetic). This requires the inclusion of clues to the sounds of the words, their phonographic component. All rights reserved.

Instantiation has little parallel in writing for non-numerical language, since there is no inherent "sheep-ness" to the letters U D U or a quartered circle. ${ }^{1}$ For these signs, specifying the intended non-numerical words means the signs had to be modified to include phonetic or determinative clues that indicated either the word itself or the type of word it was. That is, meaning signified through resemblance and convention is ambiguous in a way instantiation is not; this puts pressure on signs for non-numerical language to improve their ability to specify the words intended. This in turn requires the inclusion of phonographic and other techniques and conventions for specifying words, making writing for non-numerical language glottographic (Hyman 2006; Sampson 1999). Glottographic writing represents the words of particular languages, like the pictures representing the words "I can see you" in English through the rebus principle and the logographic, syllabic and alphabetic scripts representing the same words in Chinese, Japanese and German (fig. 4.4). As was discussed, numerical notations like "7" and " 13 " do not need such phonetic specification, and in fact, phonography reduces their ability to represent spatial, topological and geometric relations, things essential to the pattern recognition and information manipulation that is mathematics. This quality means using numbers does not require knowing the associated language, the difference between using Roman numerals and knowing their names in Latin. Words for numbers like "seven" and "thirteen," on the other hand, require both knowing the particular language and being able to read the associated script. Number-words do not have the same ability to preserve relations, make patterns accessible or manipulate information: Consider the increased difficulty of

\footnotetext{
${ }^{1}$ Geometrical shapes as used in Mesopotamian writing were not unambiguous examples of meaning by instantiation. For example, nigin 2 was a circle that as a noun meant "total, sum; (the) whole, entirety" (ePSD 2015) and as a verb meant "to encircle” and "to go around" (ePSD 2015; ETCSL 2006). In mathematical use, NIGIN meant "to make hold” (Høyrup 2002, 45). As a written form, nigin 2 might be said to instantiate its meaning. However, it does not appear to have been used to mean circle, though its semantic range was related to one. Further, it can also be said to resemble: It meant encircle because it looked like a circle. Such signs also emerged later than the numerical impressions in question (e.g., the earliest attestations of $n_{i g} i n_{2}$ are dated to the Uruk III period, 3200-3000 BCE; CDLI 2015; ePSD 2015).
} 
performing addition on a vocabulary list instead of numerical notations, or trying to do algebra with narrative paragraphs instead of equations.

J'ai additionné la surface et (le côté de) mon carré: 45'. Tu poseras $1^{\circ}$, l'unité. Tu fractionneras en deux $1^{\circ}: 30^{\prime}$. Tu multiplieras (entre eux) [30'] et $30^{\prime}: 1^{\prime}$. Tu ajouteras $15^{\prime}$ à $45^{\prime}: 1^{\circ} .1^{\circ}$ est le carré de $1^{\circ} .30^{\prime}$, que tu as multiplié (avec lui-même), de $1^{\circ}$ tu soustrairas: $30^{\prime}$ est le (côté du) carré.

(Thureau-Dangin 1936, 31)

[ 1 added the surface and (the side of) my square: $45^{\prime}$. You shall set $1^{\circ}$, the unity. You divide in two $1^{\circ}$ : $30^{\prime}$. You multiply (them) [30'] and $30^{\prime}: 15^{\prime}$. You add $15^{\prime}$ to $45^{\prime}: 1^{\circ} .1^{\circ}$ is the square of $1^{\circ}$. $30^{\prime}$, which you have multiplied (with itself), from $1^{\circ}$ you subtract: $30^{\prime}$ is the (side of) the square.]

(Høyrup 2002, 11)

Fig. 4.5. Old Babylonian mathematical tablet (BM 13901). Problem 1 from the obverse, column 1, lines 1-4 as (top) translated by Thureau-Dangin (1936, 31) and (bottom) put into equations by Høyrup (2002, 11); (middle) the English translation is by the author. All rights reserved.

Numbers have a much longer material prehistory than their involvement with writing, as they can be represented and manipulated with devices like fingers, tallies and tokens (Overmann 2018). That is, numeracy, the ability to reason with numbers, does not require numbers be written. This contrasts with non-numerical language, where handwriting is an essential part of developing literacy: Simply, if societies do not write by hand, they will not and cannot become literate. While numbers do not need to be written, handwritten notations arguably cause a dramatic change in numeracy. This is because of the neurological reorganisation that occurs when signs are handwritten, a phenomenon that includes signs for numbers. Handwriting numbers is associated with three distinct elaborational effects:

1. Numbers that are not written are collections, like seven fingers, seven notches on a tally or seven cone-shaped tokens. Numbers that are written become entities, recognised topologically through their features. This is true even if they are composed of discrete elements, like the three strokes of the Roman numeral III or the seven wedges in the cuneiform number 7 .

2. Functionally, written numbers are concise to a degree other material forms of numbers are not. Concision let relations like multiplication and reciprocity be collected into tables, which scribes learned as part of their training. This data would redefine numbers through their relations to each other, making them entities in a relational system.

3. Written non-numerical language was critical to developing mathematics. As writing became more expressive, it was used to record calculations, not as results, as was true with earlier technologies like tokens, and not as equations, the more elaborated form we would use today. Instead, calculations were recorded as narrative descriptions, like the 2nd millennium area calculation on the Old Babylonian mathematical tablet known as BM 13901 (Høyrup 1993, 2002, 2010, 2013), an extract of which is shown in fig. 4.5. It would take another several millennia for such narrative descriptions to be refined as semasiographic forms like our plus and minus signs (Schulte 2015). 
Numerical representations instantiate quantity, and quantity is something humans perceive through an evolutionarily ancient ability, the number-sense we share with other species (Coolidge and Overmann 2012; Piazza and Izard 2009). Our perception of quantity means that we can recognise small quantities —one, two and three-without counting (Dehaene 2003; Fechner 1860; Weber 1834). And without counting, quantities larger than about four are just "many," but in this range we appreciate bigger and smaller in groups, assuming the difference is above a threshold of noticeability. Respectively, these abilities are called subitisation and magnitude appreciation.

How our perceptual experience of quantity affects multielement numerical signs like those of cuneiform is shown with tally marks in fig. 4.6. The lowest, one through three, can be appreciated without counting because they are subitisable. More than about four marks are difficult to appreciate because there are more than we can subitise. In this range, we appreciate differences in magnitude, like seeing that on the lower row, there are fewer to the left and more to the right. This perceptual experience influences numerical form. Groups with subitisable elements are appreciable, so their forms neither need nor undergo much alteration. Groups higher than the subitising range are rearranged as subitisable subgroups. As quantity continues to increase, these too become increasingly difficult to appreciate, so at some point-ten in cuneiform - they might be "bundled" or grouped. In between subitising and bundling, subitisable subgroups remain under pressure to be counted, making it likely they will eventually simplify as forms that do not involve counting.

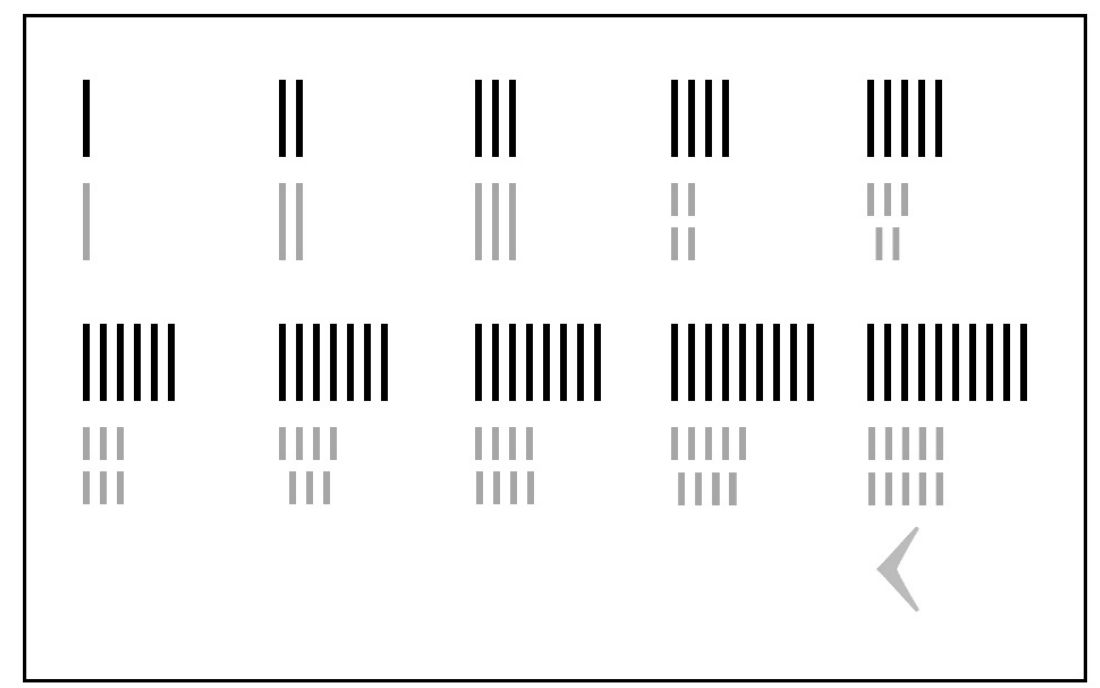

Fig. 4.6. Tally marks for the numbers one through ten. Unmodified marks appear in black, grouped or conventionalised ones in grey. One, two and three (top row, left) are subitisable and thus recognisable without modification. Four and higher fall within the range of magnitude appreciation, recognisable as bigger and smaller in groups (as for example, recognising without counting that the six to the far left in the middle row are fewer than the ten to the far right on the same row). As written notations, quantities higher than about four tend to be grouped in subitisable amounts (shown in grey below the unmodified notations). This strategy too encounters the limit on perceptual appreciation (as in the groups for seven and higher on the bottom row), necessitating the incorporation of strategies like bundling, as in the wedge that represents ten (bottom row, far right). All rights reserved.

Signs for subitisable numbers tend to be highly conserved, because they instantiate quantity in the range that we can appreciate without counting (fig. 4.7, top row). Large numbers like 7 (fig. 4.7, middle row) are initially grouped as smaller, appreciable quantities, as was true of cuneiform. Over time, these become forms that avoid counting, like the Hindu-Arabic numeral 7; once this happens, such signs become increasingly subject to mechanisms that 
change written forms, like visual distinguishability and individuation. For both these categories, semasiography means that numbers can be-and often are-adopted across languages and cultures without phonetic or semantic adaptation. This limits the amount of change these written forms undergo in transmission across languages and cultures.

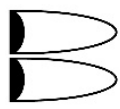

Archaic

$3350 \mathrm{BCE}$

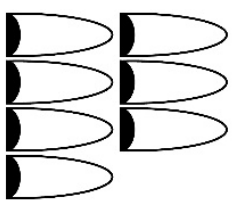

Archaic

$3350 \mathrm{BCF}$

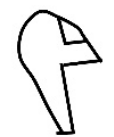

Archaic

(Sumerian?)

$3100 \mathrm{BCF}$

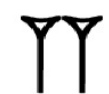

\section{Cuneiform}

1900 BCE

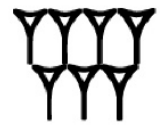

Cuneiform

$1900 \mathrm{BCE}$

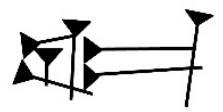

Cuneiform

(Akkadian)

$2000 \mathrm{BCF}$

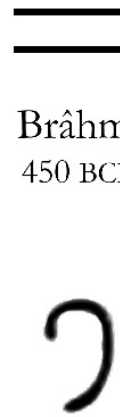

Brâhmî

$450 \mathrm{BCF}$

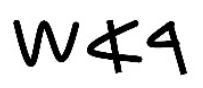

Alphabet

(Phoenician)

$500 \mathrm{BCF}$

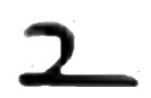

Maghribi

875 CE

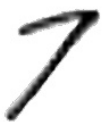

Maghribi

$875 \mathrm{CE}$.

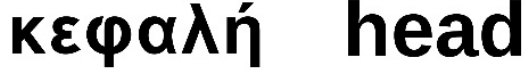

\author{
Alphabet \\ (Greek) \\ $750 \mathrm{BCF}$
}

Fig. 4.7. Change in numerical and non-numerical signs. The signs shown are related, but as represented, the lineages are incomplete. Signs for numbers instantiate, placing them under distinct neurofunctional pressures influencing their forms and how these forms change as they are adopted across languages and cultures. Signs for subitisable numbers are under the least pressure, so their form is conserved to a high degree; signs for numbers above the subitising range are under pressure to simplify as forms that do not require counting, which subjects them to the processes and mechanisms of writing change. Non-numerical signs must incorporate phonography to reduce ambiguity about which words they intend; phonographic clues increase the visual complexity of these signs, subjecting them to the greatest amount of change in form as they transmit across languages and cultures. Data sourced and images redrawn from Chrisomalis (2010), Ifrah (2000), Nissen (1986), Papadoupoulos (2016), Tompack (1978) and the CDLI. All rights reserved.

By comparison, writing for non-numerical language undergoes the most change. It is already under pressure to achieve greater semantic and phonetic specificity. When a system of writing is adapted to different languages, it initially does a poor job of representing at least some concepts and sounds, by an amount that varies with the affinities between cultures and languages. This keeps writing under pressure to specify concepts and sounds, including those of the adopting populations. This same pattern holds in Chinese (not shown; interested readers may consult Overmann 2020). Subitisable numbers change the least, large numbers by an intermediate amount and non-numerical words the most. This is despite the fact that transmission occurs across a relative homogeneity of language and culture. The form of the higher numbers additionally suggests they had been available for some time, long enough to become forms that did not require counting, before they appeared in the oracle bones. 
When change in the material form of written numbers is considered and contrasted with change in writing for non-numerical language, the overall pattern that emerges is this: Signs for numbers instantiate; so small numbers conserve, while large numbers simplify, and both are relatively insensitive to changes in languages and cultures. Signs for non-numerical language signify, so they must specify meanings and sounds, and this subjects them to the greatest amount of change, especially when they transmit across languages and cultures.

\section{Concluding Thoughts}

Modelling how the material form of writing changed in original contexts and interpreting that change through the theories and methods of cognitive archaeology is a unique way to analyse writing systems, one with the potential to realize novel insights. As reviewed here, this type of analysis has shed new light on the question of how societies of average people were able to achieve a complex cultural system like literacy (also see Overmann 2016, 2017, 2019). This required them to sustain a particular behaviour with a specific material form (writing, as verb and noun respectively) over generations. Each generation's engagement of writing changed their behaviours and psychological processing incrementally, enabling them to change the form of writing, however slightly. Change in the form of writing, in turn, accumulated and redistributed the incremental behavioural and psychological changes in the users. This iterative process would ultimately realize a material form and an associated cognitive state-script and literacy - that were well beyond what any one individual could have invented.

The model has the potential to generate further insights. Several ways in which it might be formalized and expanded were discussed. Some proposals would add depth, detail and rigour to the examination of how literacy emerges from the collective practice of writing. Another proposal for the model's expansion concerned the social use of tools and their collective effects. Work on this front is ongoing: for example, insights gained from analysing writing as a self-organizing system were recently applied to lithic technologies as they are known in the archaeological record of some 2 million years ago as part of a multiyear collaboration on 4E cognition in the Lower Palaeolithic (Overmann 2020). Change in the material form of written numbers also seems particularly appropriate for this type of analysis and was accordingly discussed here at some length. The initial conclusion is that written representations for numbers and language experience distinct neurofunctional pressures that influence the forms they take, how these forms transmit across languages and cultures and how these forms change over time.

An approach wherein writing is treated as a material form tractable to the theories and methods of cognitive archaeology has the potential to illuminate the processes whereby complex cultural systems developed in ancient times. It can also give us insight into the coevolution of cognition and culture more generally, in technologies and cognitive states beyond writing and literacy, and in time periods beyond the ancient world-including our own present and future.

\section{Acknowledgements}

This project has received funding from the European Union's Horizon 2020 research and innovation program under grant agreement No. 785793. 


\section{References}

Amalric, M. and Dehaene, S. (2016) 'Origins of the brain networks for advanced mathematics in expert mathematicians', Proceedings of the National Academy of Sciences of the United States of America 113, 4909-4917.

Bird, S. (1998) 'Strategies for representing tone in African writing systems: A critical review', 1-33. http://cogprints.org/2174/5/wll2.pdf

Bird, S. (1999) 'When marking tone reduces fluency: An orthography experiment in Cameroon', Language and Speech 42, 83-115.

Bramanti, A. (2015) 'Rethinking the writing space: Anatomy of some early dynastic signs' in Devecchi, E., Müller, G. G. W. and Mynářová, J. (eds), Proceedings of the 60e Rencontre Assyriologique Internationale, Warsaw 2014: Current Research in Cuneiform Palaeography, Gladbeck, 31-47.

Brannon, E. M. (2005) 'The independence of language and mathematical reasoning', Proceedings of the National Academy of Sciences of the United States of America 102, 3177-3178.

Brigham, J. C., Bennett, L. B., Meissner, C. A. and Mitchell, T. L. (2007) 'The influence of race on eyewitness memory' in Lindsay, R. C. et al. (eds), Handbook of Eyewitness Psychology. Vol. II, Memory for People, New York, 257-281.

Carreiras, M., Monahan, P. J., Lizarazu, M., Duñabeitia, J. A. and Molinaro, N. (2015) 'Numbers are not like words: Different pathways for literacy and numeracy', NeuroImage 118, 79-89.

CDLI (Cuneiform Digital Library). (2015) Oxford: Oriental Institute, University of Oxford. https://cdli.ucla.edu/

Charlton, S. G. and Starkey, N. J. (2011) 'Driving without awareness: The effects of practice and automaticity on attention and driving', Transportation Research Part F: Traffic Psychology and Behaviour 14, 456-471.

Chrisomalis, S. (2010) Numerical Notation: A Comparative History, Cambridge.

Clark, A. (2008) Supersizing the Mind: Embodiment, Action, and Cognitive Extension, New York.

Cammarosano, M. (2014) 'The cuneiform stylus', Mesopotamia XLIX, 53-90.

Clark, A. and Chalmers, D. J. (1998) 'The extended mind', Analysis 58, 7-19.

Comrie, B. (1989) Language Universals and Linguistic Typology (2nd ed.), Chicago.

Coolidge, F. L. and Overmann, K. A. (2012) 'Numerosity, abstraction and the evolution of symbolic thinking', Current Anthropology 53, 204-225.

Cooper, J. S. (1996) 'Sumerian and Akkadian' In Daniels, P. T. and Bright, W. (eds), The World's Writing Systems, New York, 37-57.

Cooper, J. S. (2004) 'Babylonian beginnings: The origin of the cuneiform writing system in comparative perspective' in Houston, S. D. (ed.), The First Writing: Script Invention as History and Process, Cambridge, 71-99.

Coulmas, F. (2003) Writing Systems: An Introduction to their Linguistic Analysis, Cambridge.

Dehaene, S. (2003) 'The neural basis of the Weber-Fechner law: A logarithmic mental number line', Trends in Cognitive Sciences 7, 145-147.

Dehaene, S. and Cohen, L. (2007) 'Cultural recycling of cortical maps’, Neuron 56, 384-398.

Dehaene, S. and Cohen, L. (2011) 'The unique role of the visual word form area in reading', Trends in Cognitive Sciences 15, 254-262.

Edzard, D. O. (1980) 'Sumerisch 1 bis 10 in Ebla', Studi Eblaiti III, 121-127.

Englund, R. K. (1998) 'Texts from the Late Uruk period' in Bauer, J., Englund, R. K. and Krebernik, M. (eds), Mesopotamien: Späturuk-Zeit und Frühdynastische Zeit, Freiburg, 15-233. 
ePSD (electronic Pennsylvania Sumerian Dictionary). (2015) Philadelphia: Museum of Anthropology and Archaeology, University of Pennsylvania. http://psd.museum.upenn.edu/

ETCSL (Electronic Text Corpus of Sumerian Literature) (2006) Oxford: Oriental Institute, University of Oxford. http://etcsl.orinst.ox.ac.uk/

Fechner, G. T. (1860) Elemente der Psychophysik, Leipzig.

Friberg, J. (1986) 'The early roots of Babylonian mathematics III. Three remarkable texts from ancient Ebla', Vicino Oriente 6, 3-25.

Giovanni, F. B. A. (1994) 'Order of strokes writing as a cue for retrieval in reading Chinese characters', European Journal of Cognitive Psychology 6, 337-355.

Greenberg, J. H. (1978) ‘Generalizations about numeral systems’ in Greenberg, J. H. (ed.), Universals of Human Language, Vol. 3, Stanford, 249-295.

Høyrup, J. (1993) 'On subtractive operations, subtractive numbers, and purportedly negative numbers in Old Babylonian mathematics', Zeitschrift für Assyriologie und Vorderasiatische Archäologie 83, 42-60.

Høyrup, J. (2002) Lengths, Widths, Surfaces: A Portrait of Old Babylonian Algebra and Its Kin, New York.

Høyrup, J. (2010) 'Old Babylonian "algebra”, and what it teaches us about possible kinds of mathematics’, Ganita Bhāratī 32, 87-110.

Høyrup, J. (2013) ‘Geometry, Mesopotamian’ in Bagnall, R. S. et al. (eds), The Encyclopedia of Ancient History, Malden.

Hutchins, E. (1995) Cognition in the Wild, Cambridge.

Hutto, D. D. and Myin, E. (2013) Radicalizing Enactivism: Basic Minds without Content, Cambridge.

Hyman, M. D. (2006) ‘Of glyphs and glottography’, Language and Communication 26, 231-249.

Ifrah, G. (2000) The Universal History of Numbers: From Prehistory to the Invention of the Computer (Bellos, D. et al., trans.), New York.

James, K. H. and Engelhardt, L. (2012) 'The effects of handwriting experience on functional brain development in pre-literate children', Trends in Neuroscience and Education 1, 32-42.

Jones, A. M., \& Boivin, N. (2010) 'The malice of inanimate objects: Material agency', in Hicks, D. and Beaudry, M. C. (eds), The Oxford Handbook of Material Culture Studies, Oxford, 333-351.

Keller, C. M. and Keller, J. (1996) Cognition and Tool Use: The Blacksmith at Work, Cambridge.

Kelly, P. (2019) 'Writing systems invented by non-literates and what they tell us', paper presented at the Contexts of and Relations between Early Writing Systems (CREWS) conference Exploring the Social and Cultural Contexts of Historic Writing Systems, 14-16 March 2019, University of Cambridge.

Kirchhoff, M. D. (2009) 'Material agency: A theoretical framework for ascribing agency to material culture', Techne: Research in Philosophy and Technology 13, 206-220.

Koffi, E. N. (2014) 'Towards an optimal representation of tones in the orthographies of African languages’, Linguistic Portfolios 3, 163-190.

Konnikova, M. (2014) 'What's lost as handwriting fades' in The New York Times, https://www.nytimes.com/2014/06/03/science/whats-lost-as-handwriting-fades.html

Krispijn, T. J. H. (2012) 'Writing Semitic with cuneiform script: The interaction of Sumerian and Akkadian orthography in the second half of the third millennium BC' in De Voogt, A. and Quack, J. F. (eds), The Idea of Writing: Writing across Borders, Leiden, 181-218.

Logan, G. D. (1992) 'Attention and preattention in theories of automaticity', American Journal of Psychology 105, 317-339. 
Longcamp, M., Zerbato-Poudou, M.-T. and Velay, J.-L. (2005) 'The influence of writing practice on letter recognition in preschool children: A comparison between handwriting and typing', Acta Psychologica 119, 67-79.

Malafouris, L. (2004) 'The cognitive basis of material engagement: Where brain, body and culture conflate' in DeMarrais, E., Gosden, C. and Renfrew, C. (eds), Rethinking Materiality: The Engagement of Mind with the Material World, Cambridge, 53-61.

Malafouris, L. (2008) ‘At the potter's wheel: An argument for material agency’ in Malafouris, L. and Knappett, C. (eds), Material Agency: Towards a Non-Anthropocentric Approach, New York, 19-36.

Malafouris, L. (2010) 'Knapping intentions and the marks of the mental' in Malafouris, L. and Renfrew, C. (eds), The Cognitive Life of Things: Recasting the Boundaries of the Mind, Cambridge, 13-27.

Malafouris, L. (2013) How Things Shape the Mind: A Theory of Material Engagement, Cambridge.

Malafouris, L., Gosden, C. and Overmann, K. A. (eds) (2014) Pragmatics and Cognition, Vol., 22, Special Issue: Creativity, Cognition and Material Culture, Amsterdam.

Malafouris, L. and Knappett, C. (eds) (2008) Material Agency: Towards a Non-Anthropocentric Approach, New York.

McCandliss, B. D., Cohen, L. and Dehaene, S. (2003) 'The visual word form area: Expertise for reading in the fusiform gyrus', Trends in Cognitive Sciences 7, 293-299.

Nakamura, K., Kuo, W.-J., Pegado, F., Cohen, L., Tzeng, O. J.-L. and Dehaene, S. (2012) ‘Universal brain systems for recognizing word shapes and handwriting gestures during reading', Proceedings of the National Academy of Sciences of the United States of America 109, 20762-20767.

Newen, A., De Bruin, L. and Gallagher, S. (eds) (2018) The Oxford Handbook of 4E Cognition, Oxford.

Nissen, H. J. (1986) ‘The archaic texts from Uruk’, World Archaeology 17, 317-334.

Nissen, H. J., Damerow, P. and Englund, R. K. (1993) Archaic Bookkeeping: Early Writing and Techniques of Economic Administration in the Ancient Near East (Larsen, P., trans.), Chicago.

Olson, D. R. (1994) The World on Paper: The Conceptual and Cognitive Implications of Writing and Reading, Cambridge.

Overmann, K. A. (2020) 'Writing system transmission and change: A neurofunctional perspective' in Gabriel, G. and Payne, A. (eds), Signs - Sounds - Semantics: Nature and Transformation of Writing Systems in the Ancient Near East: Papers presented at the 64th Rencontre Assyriologique Internationale, University of Innsbruck, 16-20 July 2018, Berlin.

Overmann, K. A. (2016) 'Beyond writing: The development of literacy in the Ancient Near East', Cambridge Archaeological Journal 26, 285-303.

Overmann, K. A. (2017) 'Thinking materially: Cognition as extended and enacted', Journal of Cognition and Culture 17, 381-400.

Overmann, K. A. (2018) 'Updating the "abstract-concrete" distinction in Ancient Near Eastern numbers', Cuneiform Digital Library Journal 1, 1-22.

Overmann, K. A. (2020) 'The material difference in human cognition', Adaptive Behavior.

Overmann, K. A. and Wynn, T. (2019a) 'Materiality and human cognition', Journal of Archaeological Method and Theory 26, 457-478.

Overmann, K. A. and Wynn, T. (2019b) 'On tools making minds: An archaeological perspective on human cognitive evolution', Journal of Cognition and Culture 19, 39-58.

Papadoupoulos, J. K. (2016) 'The early history of the Greek alphabet: New evidence from Eretria and Methone', Antiquity 90, 1238-1254.

Perfetti, C. A. and Tan, L.-H. (2013) 'Write to read: The brain's universal reading and writing network', Trends in Cognitive Sciences 17, 56-57. 
Pettinato, G. (1981) 'La pronuncia sumerica dei numeri da 1 a 10 in un testo lessicale di Ebla', Annali Istituto Orientale di Napoli Roma 41, 141-143.

Piazza, M. and Izard, V. (2009) 'How humans count: Numerosity and the parietal cortex', Neuroscientist 15, 261-273.

Ravid, D. and Haimowitz, S. (2006) 'The vowel path: Learning about vowel representation in written Hebrew', Written Language and Literacy 9, 67-93.

Rayner, K., White, S. J., Johnson, R. L. and Liversedge, S. P. (2006) 'Raeding wrods with jubmled lettres: There is a cost', Psychological Science 17, 192-193.

Roux, F., Dufor, O., Giussani, C., Wamain, Y., Draper, L., Longcamp, M. and Démonet, J. (2009) 'The graphemic/motor frontal area Exner’s area revisited', Annals of Neurology 66, 537-545.

Sampson, G. (1999) 'Writing systems' in Wilson, R. A. and Keil, F. C. (eds), The MIT Encyclopedia of the Cognitive Sciences, Cambridge, 894-896.

Schmandt-Besserat, D. (1978) 'The earliest precursor of writing', Scientific American 238, 50-59.

Schmandt-Besserat, D. (1992) How Writing Came About, Austin.

Schulte, S. M. L. (2015) Writing the History of Mathematical Notation: 1483-1700, Boston.

Sülzenbrück, S., Hegele, M., Rinkenauer, G. and Heuer, H. (2011) 'The death of handwriting: Secondary effects of frequent computer use on basic motor skills', Journal of Motor Behavior 43, 247-251.

Taylor, J. (2011) 'Tablets as artefacts, scribes as artisans' in Radner, K. and Robson, E. (eds), The Oxford Handbook of Cuneiform Culture, Cambridge, 5-31.

Taylor, J. (2015) ‘Wedge order in cuneiform: A preliminary survey’ in Devecchi, E., Müller, G. G. W. and Mynářová, J. (eds), Proceedings of the 60e Rencontre Assyriologique Internationale, Warsaw 2014: Current Research in Cuneiform Palaeography, Gladbeck, 1-30.

Thureau-Dangin, F. (1936) 'L'équation du deuxième degré dans la mathématique babylonienne: D’après une tablette inédite du British Museum', Revue d'Assyriologie et d'Archéologie Orientale 33, 27-48.

Tompack, R. S. (1978) A Comparative Semitic Lexicon of the Phoenician and Punic Languages, Missoula.

Tucha, O., Tucha, L. and Lange, K. W. (2008) 'Graphonomics, automaticity and handwriting assessment', Literacy 42, 145-155.

Varley, R. A., Klessinger, N. J. C., Romanowski, C. A. J. and Siegal, M. (2005) 'Agrammatic but numerate', Proceedings of the National Academy of Sciences of the United States of America 102, 3519-3524.

Veldhuis, N. (2011) 'Levels of literacy' in Radner, K. and Robson, E. (eds), The Oxford Handbook of Cuneiform Culture, Cambridge, 68-89.

Veldhuis, N. (2012) 'Cuneiform: Changes and developments' in Houston, S. D. (ed.), The Shape of Script: How and Why Writing Systems Change, Santa Fe, 3-24.

Veldhuis, N. (2014) History of the Cuneiform Lexical Tradition, Münster.

Weber, E. H. (1834) De Pulsu, Resorptione, Auditu et Tactu, Leipzig.

Wynn, T. and Coolidge, F. L. (2014) 'Technical cognition, working memory and creativity', Pragmatics and Cognition 22, 45-63.

Wynn, T. and Coolidge, F. L. (2010) 'How Levallois reduction is similar to, and not similar to, playing chess', in Nowell, A. and Davidson, I. (eds), Stone Tools and the Evolution of Human Cognition, Boulder, 83-104. 